\title{
O campo de estágio como objeto de pesquisa durante o estágio supervisionado de espanhol na faculdade de letras da UFG
}

\author{
Cleidimar Aparecida Mendonça e Silva
}

Universidade Federal de Goiás

\author{
Lucielena Mendonça de Lima \\ Universidade Federal de Goiás
}

\begin{abstract}
Resumo
Atualmente, a crescente demanda pelo estudo do espanhol como língua estrangeira (E/LE) no Brasil exige do futuro professor dessa língua uma formação cada vez mais abrangente e qualificada. O estágio, como etapa relevante nessa formação, é considerado no curso de Letras / Espanhol da UFG como uma "atitude investigativa, que envolve a reflexão e a intervenção na vida da escola”, nos termos de Pimenta e Lima (2004, p.34). Assim, o objetivo deste artigo é relatar a experiência em dois campos de estágio em 2006 (um colégio público estadual de Goiânia e o $\mathrm{CEPAE}^{1}$ ), que culminou na elaboração de trabalhos finais, os quais problematizaram questões relativas aos processos de ensino e aprendizagem de E/LE, entre elas: inclusão social, motivação, integração das quatro habilidades linguísticas, variedades sociolinguísticas, temas transversais, estágios de interlíngua, interculturalidade.
\end{abstract}

Palavras-chave: estágio, pesquisa, ensino e aprendizagem de E/LE.

\begin{abstract}
Nowadays, the increase in the demand for learning Spanish as a foreign language in Brazil (S/FL) requires more academic and professional qualifications for the future Spanish teacher. The internship, as an important stage of second language teacher education, is considered at the Letras/Spanish course at UFG as 'an investigative attitude which involves reflection and intervention in the school life', according to Pimenta and Lima (2004, p. 34). The aim of this article is to describe and discuss the experiences in 2006 in two different internship settings: a state public school in Goiânia and CEPAE (Centro de Ensino e Pesquisa Aplicada à Educação). Based on these experiences, the papers written for the internship point out different issues concerned with learning and teaching Spanish, such as social inclusion, motivation, the four linguistic skills integration, sociolinguistic varieties, cross-sectional themes, interlanguage stages, interculturality and so on.
\end{abstract}

Keywords: internship, research, spanish as a foreign language (S/FL), teaching and learning process.

\footnotetext{
${ }^{1}$ Centro de Ensino e Pesquisa Aplicada à Educação, campo de estágio para todas as licenciaturas da UFG.
} 


\section{A CONCEPÇÃO DE ESTÁGIO NOS DOCUMENTOS OFICIAIS E PPP/FL/UFG}

A partir de 2004, todos os cursos de licenciatura plena do Brasil passaram a ter uma nova configuração curricular. No que diz respeito ao número de horas para a efetivação do curso, a resolução CNE/CP 2, de 19 de fevereiro de 2002, explicita em seu Art. $1^{0}$ que são necessárias, no mínimo, 2800 horas para sua integralização, assim distribuídas:

I - 400 horas de prática como componente curricular, vivenciadas ao longo do curso;

II - 400 horas de estágio curricular supervisionado a partir da segunda metade do curso;

III - 1800 horas para os conteúdos curriculares de natureza científico-cultural;

IV - 200 horas para outras formas de atividades acadêmico-científico-culturais.

A divisão da graduação, modalidade licenciatura, nas horas referidas, conforme escrito nas resoluções, vem recebendo muitas críticas de educadores e pesquisadores brasileiros. Para Pimenta e Lima (2004, p.87), o estágio, por encontrar-se "separado tanto das atividades práticas quanto das denominadas científico-culturais”, favorece o treinamento e não a reflexão sobre a teoria e a prática.

Outro ponto central exposto nas diretrizes CNE/ CP 1, de 18 de fevereiro de 2002, refere-se à pesquisa, que deve ter seu foco no processo de ensino e aprendizagem como condição para se compreender a forma de construção do conhecimento. Uma vez mais, as autoras anteriormente citadas questionam as diretrizes por considerarem que a formação de professores fica limitada e se perguntam "como os futuros professores aprenderão a pesquisar no ensino se em sua formação a pesquisa está ausente?” (Pimenta; Lima, 2004, p.87).

Em consonância com as resoluções do MEC, foi elaborado o PPP da Faculdade de Letras, em 2003, para expressar a concepção que a instituição tem de currículo e ensino superior. No que se refere ao estágio supervisionado, o documento observa o que as diretrizes orientam: o estágio deve realizar-se em uma escola-campo e articulado com 
o restante do curso (CNE/ CP 1, 2002). E ainda, "sob a forma de uma ação desenvolvida enquanto vivência profissional prolongada, sistemática, intencional [e] acompanhada”, conforme o Fórum De Pró-Reitores De Graduação Das Universidades Brasileiras (2002, p. 23).

O PPP/FL (2003) também considera que o estágio é uma oportunidade de conhecimento do real em situação de trabalho. Dessa forma, revela-se como espaço de construção do professor como sujeito que tem domínio de sua própria prática e de seu papel social. Concebe-se o estágio, portanto, não somente como observação e regência, mas nos vários aspectos da formação profissional, conforme propõe Paiva (2005):

1. observação de reuniões de pais e professores, conselho de classe, exame de regulamentos e estatutos da escola escolhida, entrevistas com coordenadores, diretores, orientadores e professores, análise dos projetos pedagógicos e demais atividades [...];

\section{2. [...] preparação e pilotagem de material didático;}

3. observação das aulas e engajamento em atividades extracurriculares [...] classes de aceleração, oficina de redação, clubes de conversação para línguas estrangeiras, auxílio na avaliação de alunos [...];

4. regência de algumas aulas;

5. engajamento em projetos de pesquisas no contexto de estágio [...].

A necessidade de se conhecer no estágio a complexidade que envolve o contexto escolar e as condições em que os processos de ensino e aprendizagem se efetivam é também corroborada pelas autoras Pimenta e Lima (2004, p.163-164) quando postulam:

[e]sse conhecimento envolve o estudo, a análise, a problematização, a reflexão e a proposição de soluções às situações de ensinar, aprender e elaborar, executar e avaliar projetos de ensino, não apenas nas salas de aula, mas também na escola e demais espaços educativos que as envolvem e determinam. Assim, o lócus do estágio se estende para além do espaço escolar e da sala de aula, configurando uma possibilidade de leitura do mundo, conforme Paulo Freire. Nessa perspectiva o estágio tem sentido de complementação, trazendo elementos de compreensão da totalidade social que respinga na atividade docente e no cotidiano da sala de aula. 
O PPP/FL (2003) ainda expressa que, conforme a legislação vigente, podem complementar a formação docente "as tecnologias de informação, incluídos o computador e o vídeo, narrativas orais e escritas de professores, produções de alunos, situações simuladoras e estudos de caso” (CNE/ CP 1, 2002), que se encontram em sintonia com um dos princípios norteadores do projeto pedagógico dos cursos: "a aprendizagem deverá ser orientada pelo princípio metodológico geral, que pode ser traduzido pela ação-reflexão-ação e que aponta a resolução de situações-problema como uma das estratégias didáticas privilegiadas” (CNE/ CP 1, 2002).

O envolvimento em situações-problema e a postura crítico-reflexiva é condição sine qua non para que os estagiários possam discutir as questões da realidade vivenciada. É o que consideram Pimenta e Lima (2004, p. 45) ao afirmarem que "a aproximação à realidade só tem sentido quando tem conotação de envolvimento e de intencionalidade”, e Mesquita (2005) ao entender que tal postura proporciona um reanalisar e re-significar dessa realidade.

Vale ressaltar, ainda, uma importante orientação presente no PPP/FL (2003): o entendimento de que o estágio supervisionado é uma ação a ser desenvolvida na interface com o projeto político pedagógico da unidade formadora e da escola em que é realizado, uma vez que essa parceria garantiria benefícios para ambas as instituições, pois, segundo Pimenta e Lima (2004, p. 115),

[a] pesquisa é componente essencial das práticas de estágio [grifo nosso], apontando novas possibilidades de ensinar e aprender a profissão docente, inclusive para os professores formadores, que são convocados a rever suas certezas, suas concepções do ensinar e do aprender e seus modos de compreender, de analisar, de interpretar os fenômenos percebidos nas atividades de estágio: a reflexão da prática como ponto de partida e de chegada.

\section{A CONCEPÇÃO DE ESTÁGIO SUPERVISIONADO EM ESPANHOL NA FL/UFG}

A partir do exposto, o estágio de espanhol reitera que teoria e prática não se separam. Assim, entende que a formação pré-serviço deve possibilitar "um questionamento do papel da prática em relação aos conceitos teóricos, da relação entre os saberes experienciais e os saberes exteriorizados” (Giménez, 2004, p.186). Esse fato pode propiciar a vivência dos processos que fundamentam a prática profissional e que compõem os processos de ensino e aprendizagem. 
Nesse sentido, Pimenta (1994), em estudo realizado em escolas de formação de professores, conclui que o estágio, ao contrário do que se pensava antes, não é atividade prática, mas teórica, instrumentalizadora da práxis docente, e capaz de transformar a sociedade. Dessa forma, ele é definido como "atividade teórica de conhecimento, fundamentação, diálogo e intervenção na realidade (...)” (Pimenta; Lima, 2004, p. 45), ideia por nós defendida neste trabalho. O estágio como lócus privilegiado para desenvolver a atitude crítico-investigativa e a busca pela autonomia é também explicitado por Mesquita (2005, p.83), ao considerar que, diante dos constantes desafios,

o estagiário deve exercitar o hábito de buscar saberes científicos, específicos e educacionais, e de praticar a sensibilidade da indagação na identificação e avaliação das ambigüidades e incertezas dos conflituosos contextos escolares e não escolares. Afinal, confrontar teorias e experiências significa debruçar-se sobre temas relativos ao cotidiano escolar ligando-os a contextos institucionais, políticas públicas e anseios individuais.

Abib (2002) também compreende a necessidade de o discente-docente comportar-se como sujeito responsável pela elaboração dos conhecimentos necessários para a sua prática de sala de aula. Essa postura rompe com a passividade que permeia a atuação de muitos estagiários, os quais não se sentem responsáveis por sua formação e pelos problemas que afetam os processos de ensino e aprendizagem. A tradicional divisão do trabalho de estágio nas etapas de observação, semi-regência e regência corrobora essa postura passiva do futuro professor e permite que ele faça uma série de críticas ao processo apenas baseando-se em impressões superficiais, sem o devido rigor da apreciação investigativa.

No estágio de espanhol, procuramos evitar esse tipo de comportamento e os estagiários são alertados para a necessidade de inserção na realidade da escola-campo. A ideia é que eles se engajem no processo educativo como pesquisadores, propondo uma discussão mais ampliada com todos os sujeitos nele envolvidos: professores, coordenação, direção, alunos... As sessões de reflexão, momentos de confronto entre a realidade vivenciada e as teorias estudadas na universidade, também servem de embasamento para a discussão dos desafios enfrentados.

Dessa forma, há uma maior possibilidade de acontecer o que acredita Mesquita (2005, p.37), ao considerar que "há um desejo latente desses futuros profissionais de aprender e saber como ensinar, de conseguir, com qualidade e sucesso, pensar e 
repensar o seu fazer pedagógico”. Assim, o aluno-professor pode ir descobrindo, com uma atitude investigativa, como tornar-se um profissional atento e sensível aos problemas da prática.

Nesse sentido, vale a pena ressaltar o perfil de profissional esperado para atuar na educação neste século e que é expresso nos quatro pilares propostos: aprender a conhecer, aprender a fazer, aprender a viver juntos e aprender a ser (Delors, 1996). No que diz respeito ao estágio, o primeiro pilar significa a necessidade de o futuro professor analisar a realidade da escola-campo para perceber suas dificuldades; o segundo se relaciona com a forma de atuar diante dessa realidade; o terceiro reivindica a importância do respeito interpessoal nas relações educacionais e o quarto expressa a busca pelo equilíbrio pessoal para uma melhor atuação docente.

Assim, Nóvoa (2005), importante pesquisador português na área de formação de professores, chama a atenção para três dilemas que considera cruciais nos processos de ensino e aprendizagem para atuação docente neste século: a questão da comunidade, a questão da autonomia e a questão do conhecimento. O primeiro dilema se explica pela necessidade de redefinição do sentido social do trabalho docente no novo espaço público da educação. O segundo aborda a urgência em se repensar esse trabalho numa lógica de projetos e de cooperação. E o terceiro demonstra a preocupação em reconstruir o conhecimento profissional a partir de uma reflexão prática e deliberativa.

Alarcão (1998) sintetiza que o professor (o de espanhol, neste caso) deve ser capaz de pensar e trabalhar por si, mas também de pensar e trabalhar com os outros. Esse é um dos princípios do estágio concebido como pesquisa, ou seja, a necessidade de responder aos anseios de adequação da própria prática, mas de contribuir também com os pares e com os processos de ensino e aprendizagem de forma global.

Outro relevante aspecto a considerar no processo de formação dos futuros professores de LEs é como o estágio pode ajudá-los a desenvolver sua abordagem de ensinar. Para Almeida Filho (1998, p. 13), “uma abordagem se constitui numa filosofia de trabalho, verdadeira força potencial capaz de orientar as decisões e ações do professor nas distintas fases da operação global de ensino”. O autor compreende que, em sua trajetória formativa, os professores desenvolvem uma abordagem de ensinar baseada em experiências anteriores de antigos mestres, em concepções teóricas e nas próprias experiências vivenciadas em sala de aula. 
O estágio, por propiciar a vivência de conflitos e a busca de soluções por meio de uma discussão teórico-prática, é imprescindível nessa etapa de aquisição de uma abordagem de ensinar que pode receber influências de diversos fatores envolvidos no contexto escolar e nos processos de ensino e aprendizagem: da instituição, dos professores, dos alunos, do tipo de relação que entre esses sujeitos se constrói etc.

Portanto, considerando as orientações presentes nos documentos federais e no PPP FL/UFG (2003), e a posição dos autores citados, o estágio de espanhol é visto como um momento ímpar para o desenvolvimento de uma postura investigativa por parte do futuro professor dessa língua. O campo de estágio se concebe como lócus privilegiado para a aquisição de uma atitude crítico-reflexiva sobre o seu processo de formação, sua prática pedagógica e sua identidade profissional.

\section{A CONCEPÇÃO DE FORMAÇÃO DE PROFESSORES EM DPEE E ESTÁGIO DE ESPANHOL}

Segundo Richards (1990), existem duas perspectivas bem opostas, porém recorrentes nos cursos de formação de professores: treinamento (“micro-perspectiva”), que prepara os alunos para praticar determinadas habilidades e técnicas, em suma, o que se deve fazer durante as aulas; e educação (“macro-perspectiva”), ou seja, formação a partir de um procedimento holístico que "implica em fazer generalizações e inferências que vão além do que pode ser observado diretamente na forma de processos quantificáveis de sala de aula” (Richards, 1990, p.4). Day (1990), citando Leihardt e Smith (1984), afirma que os dois tipos de conhecimento que o aluno-professor deve adquirir ou desenvolver durante sua formação são o conhecimento sobre como ensinar o conteúdo ("subject-matter-knowledge”) e o conhecimento de elementos não relacionados ao conteúdo a ser ensinado, mas a questões mais gerais, como as expectativas do professor e as ações na sala de aula (“action-system-knowledge”).

As aulas de Didática e Prática de Ensino de Espanhol (DPEE) e Estágio de Espanhol que desenvolvemos baseiam-se na segunda perspectiva proposta por Richards (1990), por isso oferecemos, aos futuros professores, oportunidades em sala de aula para que comecem a observar as realidades das salas de aula reais nas escola-campo. Considerando que faz parte dos objetivos da didática mediar e possibilitar as interações dos alunos com a matéria (objeto de conhecimento), criamos oportunidades para 
exercitar, na prática, os conhecimentos teóricos estudados, pois nossos alunos, que fazem didática no quinto e último ano do curso, na maioria dos casos, nunca foram ou não são professores e sentem dificuldades para atuar como tais. Porém têm condições de interpretar e transformar os conhecimentos já adquiridos, pois possuem competência implícita, aquela advinda de experiências de antigos mestres, e já cursaram didática de português no quarto ano. Assim, não podem ser vistos somente como aprendizes de novas formas de ensinar e de comportar-se (Freeman, 1991). Por isso, é necessário que vivam situações que se assemelhem ou se aproximem das reais para que possam ter uma postura observadora, interativa e reflexiva que lhes permita administrar e solucionar situações adversas em suas práticas futuras.

Lüdke (2002), em suas pesquisas sobre a visão do formador de professores do ensino básico, detectou entre os professores do ensino médio duas concepções sobre o que é pesquisa - a acadêmica e a não acadêmica: “[n]ossos entrevistados (...) demonstraram, por um lado, uma concepção declarada bastante formal e acadêmica sobre o que é pesquisa. Por outro lado, espontaneamente, afirmavam que não era essa a pesquisa que faziam, ou deveriam fazer, em suas escolas” (p.7). Indagados sobre este último tipo de pesquisa, “as respostas se orientam para questões práticas, de confecção de material, de estratégias de ensino para diferentes alunos e coisas semelhantes. Essas respostas vêm sempre acompanhadas da explicação: ‘é dessas coisas que o professor precisa', como se a outra pesquisa, a feita na academia, não fosse capaz de provê-las” (p.8).

Os participantes que demonstraram essa concepção dicotômica de pesquisa afirmaram não ter recebido formação para a pesquisa e não haviam realizado ainda estudos de pós-graduação. Já os participantes pós-graduados não compartilharam dessa visão, pois afirmaram ser necessária a prática da pesquisa por ser “constitutiva da própria identidade do professor, que, sem a prática e a formação para a pesquisa, ficará desprovido de criatividade, de ideias próprias, de iniciativa para a construção do próprio saber diferente daquele de seus alunos, encaixando-se (...) na figura do professor repetidor” (p.8). Como ressalta Lüdke (2002, p.9), é preciso repensar essas concepções porque corre-se “o risco de hierarquização entre diferentes tipos de pesquisa para diferentes níveis de professores”. 
Acreditamos que há uma relação intrínseca entre o desenvolvimento da competência de aprendizagem ou autonomia e a realização de pesquisa durante a formação do professor porque, grosso modo, há dois tipos de alunos: os passivos e os ativos. Os primeiros, durante as sessões de orientação, do planejamento das aulas para a escola-campo e da redação do TCC, mais que orientação, querem que digamos o que é para fazer e como deve ser feito, chegando inclusive a afirmar que não receberam orientação porque não foram "treinados". Alguns poucos são ativos, ou seja, têm um gosto mais apurado para a pesquisa, pois durante as orientações se colocam numa postura mais reflexiva e já trazem idéias para serem discutidas. Nossa preocupação com essas questões se deve ao fato de entendermos que, durante a formação universitária, os futuros professores devem preparar-se tanto para o exercício do magistério, quanto para a pesquisa. Inclusive tentamos fazê-los compreender que esse é apenas o primeiro nível em sua formação, que há ainda todos os níveis de pós-graduação.

Como professoras, apresentamos essas duas concepções para evidenciar que a pesquisa acadêmica em Linguística Aplicada (LA) não é estritamente teórica porque, se é realizada como estudo de caso, vai aplicar à sala de aula do ensino básico e médio as “questões práticas”. Almeida Filho, ao divulgar um texto intitulado "O fazer atual da linguística aplicada no Brasil: foco no ensino de línguas”, no II ELARCO (UnB, 2005, p.7-8), enumerou 15 tópicos e focos temáticos, entre os quais destaca: o ensino de língua(s) diagnosticado dentro das limitações de contextos típicos de aprender/ensinar nas escolas brasileiras (principalmente do livro didático); interlíngua em fluxo normal, sinais de estabilização, correção e tratamento de erros; ensino explícito e implícito, graus de interface, gramática e enredamento semântico; ensino instrumental de línguas; novas tecnologias no ensino-aprendizagem de língua(s) e letramento e oralidade na escolarização.

Temos como objetivo levar os futuros professores a refletir diariamente a partir de cada leitura e atividade proposta porque acreditamos que a formação reflexiva do docente (Nóvoa, 1992) pode ser a mais adequada, porque pode gerar mudanças na prática futura de cada um, contribuindo efetivamente para a formação de novos cidadãos. 


\section{AS EXPERIÊNCIAS DO ESTÁGIO COMO OBJETO DE PESQUISA NAS DUAS ESCOLAS-CAMPO}

\section{A primeira escola-campo: CEPAE/UFG}

O Centro de Ensino e Pesquisa aplicado à Educação da UFG (CEPAE-GO) foi fundado em 1982, porém havia sido criado em 1966 como um Colégio de Aplicação e teve suas atividades iniciadas em 1968. Sua finalidade é ajudar na realização do ensino, da pesquisa e da extensão, como instrumentos de participação na formação de novos educadores nas diversas áreas de conhecimento, atendendo, pois, os diversos cursos de Licenciatura. A definição dessa política foi avançando em suas metas e propostas e, à medida que os projetos foram sendo pensados, construídos e fortificados, pôde-se testemunhar a consolidação do papel fundamental do CEPAE no processo de reflexão, reformulação e fortalecimento das Licenciaturas.

As funções dos Colégios de Aplicação (de várias universidades federais brasileiras) e do CEPAE-UFG são oferecer educação básica, desenvolvimento da pesquisa, experimentação de novas práticas pedagógicas, formação de professores, criação, implementação e avaliação de novos currículos, capacitação de docentes; promover um ambiente propício para uma variedade de pesquisas que possam ser realizadas por professores do ensino básico e médio, professores universitários, estagiários e outros; oferecer um laboratório de recursos humanos para a realização de experiências, desenvolvimento e aprimoramento de inovações que possam ou não estar diretamente vinculadas à pesquisa; possibilitar um ambiente adequado para a criação, testagem, implementação e avaliação de novos currículos e estratégias de ensino; propiciar um local favorável para a capacitação de docentes e de pessoal técnicoadministrativo vinculado ao ensino e permitir ao estagiário observação e participação em um ambiente educacional de qualidade, viabilizando uma prática significativa e de alto nível para os que precisam de uma experiência mais rigorosa antes de concluírem o curso de graduação. Portanto, é um lócus privilegiado como campo de Estágio para todos os alunos das licenciaturas oferecidas pela UFG e, no nosso caso, em Letras.

A matriz curricular de 1992 criou o curso de habilitação dupla em Português/ Espanhol, regime anual, com a duração de 5 anos e teve em 1994 sua primeira turma de ingressos, que se licenciou em 1998. Naquele ano, porém, o CEPAE ainda não oferecia aulas de espanhol. Portanto, não pôde servir de campo para o estágio supervisionado, o 
qual foi realizado em escolas públicas municipais implementadas através de um projeto experimental, "Escola para o Século XXI”, em turmas de terceira e quarta séries uma vez por semana (ciclo II). Esse projeto teve uma ótima aceitação por parte de todos e, no ano seguinte, a língua espanhola foi incluída como uma das línguas estrangeiras nas escolas que dele participaram. Foi realizado, inclusive, um concurso para professores em 1999, no qual todos os que haviam concluído o curso em 1998 foram aprovados.

Já em 1999, realizamos o estágio no CEPAE porque um professor substituto havia sido contratado e dava aulas para uma turma do terceiro ano do ensino médio. Assim sucedeu até 2004, quando houve uma consulta ao corpo discente, que deveria eleger uma língua estrangeira obrigatória para o ensino médio, e o espanhol foi escolhido. Portanto, desde 2005 essa língua é oferecida nas três séries, e em 2006 os alunos da oitava série do ensino básico, hoje nono ano, também passaram a ter aulas de espanhol ministradas por uma professora efetiva com nível de mestrado e dois professores substitutos.

A matriz curricular de 2003 criou a habilitação simples em Espanhol com a duração de quatro anos no regime semestral, sendo portanto 8 semestres. A primeira turma de ingressos foi de 2004, e se licenciou em 2007. O estágio supervisionado é oferecido durante os quatro últimos semestres do curso (Estágio 1, 2, 3 e 4). A avaliação se baseia nos seguintes produtos: no Estágio 1, um relatório; no Estágio 2, um artigo acadêmico; no 3, um projeto de pesquisa, e no 4, um Trabalho de Conclusão de Curso (TCC) sobre alguma questão relacionada aos processos de ensino e aprendizagem de E/LE ou ao processo de formação docente.

\section{A segunda escola-campo: colégio público estadual}

No $2^{\circ}$ semestre de 2006, foi elaborado um projeto de estágio em parceria com um colégio estadual, situado na região norte de Goiânia, que expressava os seguintes objetivos e ações a serem desenvolvidas: conhecer e diagnosticar os processos de ensino e aprendizagem do Espanhol como Língua Estrangeira (E/LE) e coletar dados sobre essa realidade para realização da regência e elaboração de um trabalho final para a disciplina de Estágio 2. As estagiárias, acompanhadas pela professora da UFG, foram às segundas-feiras para realizar o estágio no colégio e foram acompanhadas todas as turmas de $1^{\circ}$ e $3^{\circ}$ anos do ensino médio, turno matutino. 
Os procedimentos metodológicos assim se explicitaram: acompanhamento e observação das aulas nos meses de agosto e setembro, coleta de dados utilizando diversos instrumentos de pesquisa (anotações de campo, gravações em áudio, entrevistas com alunos, professores, coordenação e direção e questionários) e regência individual sobre temas linguísticos específicos, de outubro a novembro, de acordo com o programa desenvolvido pela professora.

A postura adotada pelas estagiárias pode ser considerada ativa, pois se inseriram desde os primeiros dias de convivência na nova realidade do colégio. Coube a cada uma, após o primeiro mês de contato, escolher temas problematizadores da prática pedagógica e propor discussões e encaminhamentos. Entre os principais problemas detectados, foram observados: o uso esporádico da língua espanhola pela professora em sala de aula; a falta de interesse e motivação dos estudantes para acompanhar as aulas; o número insuficiente de aulas, duas por semana, com duração de 50 minutos cada; a língua trabalhada de forma descontextualizada das demais disciplinas, não sendo tratada como relevante para a educação para a cidadania como defendem as Orientações Curriculares de Espanhol (2006); os conteúdos gramaticais cobrados a partir da memorização de regras; a falta de recursos didáticos para apoio à professora e aos alunos (não há nenhum dicionário de espanhol na biblioteca e pouquíssimos alunos possuem a fotocópia do material utilizado); a sobrecarga de trabalho realizado pela professora que ministra aulas para todas as turmas de espanhol do ensino médio, sendo sete no turno matutino e nove no noturno, em uma escola que possui 11 turmas no total em cada turno; a ausência de incentivo e horário disponível para investimento da professora em sua própria formação continuada.

A concepção de estágio assumida pelas estagiárias na realidade exposta foi um comprometimento para com a sua própria formação, atitude corroborada por Abib (2002, p. 191) ao afirmar que o "futuro professor deve exercer um controle sobre seu próprio processo de aprendizagem”. Tal fato se comprova pela escolha de temas tais como inclusão social, motivação, integração das quatro habilidades linguísticas, variedades sociolinguísticas, temas transversais, interculturalidade e estágios de interlíngua para a elaboração dos trabalhos, e também pelo planejamento e execução da regência e pelos debates nas sessões de reflexão sobre os textos teóricos dialogados com a prática. Isso é o que defende Mesquita (2005, p.37) quando considera que o estágio “é 
um momento privilegiado de encontro com a realidade e da busca por caminhos que fortaleçam suas [dos estagiários] crenças e esperanças na educação”.

Nóvoa (2005, p.15) também defende a utilização de programas de formação que desenvolvam o saber relacionar e saber relacionar-se (dilema da comunidade), o saber organizar e saber organizar-se (dilema da autonomia) e o saber analisar e saber analisarse (dilema do conhecimento), o que, em situação de formação pré-serviço, potencializa a discussão sobre a função social da LE nas instituições educativas, visando à preparação do aluno para o exercício da cidadania.

\section{OS TEMAS DOS ARTIGOS ACADÊMICOS E TCC}

Os artigos acadêmicos exigidos no Estágio 2 (2006/2) e os TCC em DPEE (2006) abordaram esses dilemas, os desafios e as dificuldades enfrentadas nas escolascampo. A metodologia utilizada para a elaboração dos mesmos foi o estudo de caso de caráter interpretativista, ou seja, baseado nas observações, impressões e avaliações do pesquisador.

Alguns temas abordados nos artigos e TCC revelaram a preocupação dos estagiários em tratar as questões observadas nos processos de ensino e aprendizagem e na própria formação docente. Por isso, a prática de ensino ou o estágio supervisionado foi dividido em três fases: observação de todos os contextos da escola, incluindo a sala de aula; aulas em pares e individuais e, na última fase, cada um deveria realizar sua pesquisa também durante as aulas ministradas, colhendo os dados sobre o seu tema específico para finalizar o TCC em formato de artigo acadêmico.

Quanto à inclusão social, foram avaliadas as condições físicas e humanas dos campos de estágio e se pôde constatar que ainda há muito a ser feito para cumprir a lei que orienta as instituições de ensino a acolher os portadores de necessidades educativas especiais. As escolas-campo não dispõem de profissionais habilitados (intérpretes de Libras) para atender a esses estudantes e tampouco oferecem um espaço físico adequado para recebê-los. A pesquisa desenvolvida com uma “cadeirante” permitiu constatar que ela ainda enfrenta problemas rotineiros como a falta de acesso ao banheiro dos alunos, não projetado para permitir a passagem de uma cadeira de rodas.

Quanto à motivação, constatou-se que o filtro afetivo dos aprendizes, espécie de barreira mental que pode auxiliar ou dificultar a aprendizagem dos conteúdos 
ministrados (Krashen, 1981), se encontra alto. Esse fato revela que há pouca motivação e isso impede que se crie um clima afetivo e propício para a aprendizagem. O uso de recursos lúdicos como jogos, vídeo e música foi destacado como elemento relevante para promover a motivação. O papel do desejo também foi ressaltado como uma força positiva que impulsiona a aprendizagem. Para isso, a língua estrangeira deve ser “desestrangeirizada” de forma paulatina e processual para ser aceita pela comunidade escolar, segundo Almeida Filho (1998). Portanto, as expectativas e perspectivas de aprendizagem de espanhol dos alunos brasileiros devem ser o centro do processo.

Quanto à cultura, o uso de textos publicitários e canções foi ressaltado como recurso que propicia motivação e ajuda a “aprender a aprender” os conteúdos gramaticais e fonético-fonológicos. As variantes sociolinguísticas, a reflexão sobre as expressões idiomáticas e as palavras consideradas vulgares ajudaram os alunos e professores a (re)conhecê-las como elementos culturais. Assim, perceberam a importância de se discutir o espanhol também em seus contextos culturais. A intenção é que percebam que a língua é herança cultural (Laraia, 1993), fato que fomenta o respeito às diferenças e o exercício da tolerância no aprendizado de uma língua estrangeira. Como exemplo, a postura intercultural foi destacada ao ser trabalhada a leitura de textos sobre a celebração do dia de finados no México, que mostra uma concepção diferente da morte se comparada com a dos católicos, tendo sido muito bem aceita por todos como uma manifestação diferente, porém própria dos descendentes das culturas indígenas, como a asteca.

Quanto à integração das quatro habilidades linguísticas, verificou-se que é possível integrá-las, cumprindo, assim, um dos princípios da abordagem comunicativa, pois é raro que em nossa vida uma dessas habilidades se realize de maneira isolada. Dessa maneira, a integração é uma condição para que a comunicação se efetive. Apesar do pouco tempo de duração de cada aula (45 ou 50 minutos), com um bom planejamento e o estabelecimento de prioridades, é possível fazer esse trabalho. Os estágios interlinguísticos foram observados na expressão oral e escrita, portanto o uso de técnicas e estratégias tais como reconhecimento do vocabulário em geral e dos falsos amigos, em particular, foi destacado como prioritário para desenvolver a compreensão leitora e a expressão escrita. O uso de estratégias de comunicação foi trabalhado para desenvolver as competências linguístico-discursivas durante a expressão oral, e as 
técnicas de auto-avaliação, a correção em pares e os deveres de casa foram exercitadas para mostrar suas possíveis contribuições no processo de produção de textos escritos. Foram realizados exercícios para detectar e corrigir as dificuldades específicas da pronúncia dos brasileiros.

Quanto aos temas transversais, isto é, conteúdos que discutem questões sociais, constatou-se que a sua inclusão em sala de aula exige uma postura crítica do professor e a conscientização sobre sua importância por parte dos alunos. A eleição de temas relativos a Ética, Saúde, Meio Ambiente, Pluralidade Cultural e Orientação Sexual foi feita por sua atualidade, abrangência nacional e até mesmo universal, pois podem ajudar os alunos a tornarem-se cidadãos mais conscientes e participativos, e o trabalho multidisciplinar propicia isso. De maneira geral, percebeu-se que a forma de integrar esses temas nas aulas de E/LE é levar o aluno a entender como a linguagem é usada, possibilitando o surgimento de novas práticas sociais por meio da criação de espaços na escola para a construção de outros discursos.

Com relação às contribuições do estágio para os processos de ensino e aprendizagem, a coordenadora e a professora de espanhol do colégio público estadual foram unânimes ao afirmar que a presença e a postura investigativa das estagiárias contribuíram para a reflexão sobre situações-problema enfrentadas no dia-a-dia do campo de estágio. No tocante à contribuição para a própria formação, afirmamos com Paiva (2003) que o estágio deve funcionar também como uma instância de formação continuada, resultado de uma “interação sistemática com as escolas de educação básica, desenvolvendo projetos de formação compartilhados”.

Considerando as realidades locais e contextuais das escolas de ensino básico e médio e os níveis de formação dos professores, acreditamos que a realidade do CEPAE é diferenciada, pois os professores são pós-graduados, realizam pesquisas com seus alunos e, ao orientar os estagiários, têm mais condições de auxiliá-los com os aspectos teóricos e práticos da pesquisa, além de possuir uma infra-estrutura mais bem equipada e ter um número reduzido de alunos por sala (em média quinze), o que pode facilitar os processos de ensino e aprendizagem. 


\section{CONSIDERAÇÕES FINAIS}

Uma primeira questão a considerar na formação pré-serviço é a necessidade de se despertar no estagiário o gosto pela pesquisa desde os primeiros contatos com o campo de estágio. Essa postura evita acomodação, passividade e alienação diante das situações-problema enfrentadas no contexto escolar, nos processos de ensino e aprendizagem de LEs e na própria formação docente. A relação entre os textos teóricos estudados na universidade e a práxis observada também foi produtiva, pois evidenciou o jeito de cada estagiário olhar, analisar, problematizar e propor encaminhamentos para as dificuldades. A autonomia foi exercida na co-responsabilidade assumida pelos discentes-docentes para com a sua própria formação. Isso se evidenciou na escolha adequada de temas para a elaboração dos trabalhos, que procuraram responder aos problemas do campo de estágio escolhido.

Portanto, ao enfatizar a pesquisa no estágio, espera-se que o futuro professor de espanhol esteja consciente de seu papel como sujeito ativo e responsável por sua formação, pela aquisição de sua identidade profissional e por sua prática docente. A intenção é que os graduandos dessa língua apreciem a escola-campo com um olhar crítico-participativo, percebendo-a como um lócus privilegiado por potencializar as "múltiplas dimensões do ser professor: o pensar, o fazer, o sentir, o compartilhar, o decidir”, como nos explica Abib (2002, p.203).

\section{REFERÊNCIAS}

Abib, M. L. V. dos S. (2002). A contribuição da prática de ensino na formação inicial de professores de Física. In Rosa, D. E. G. et al. Didática e práticas de ensino: interfaces com diferentes saberes e lugares formativos. Rio de Janeiro: DP \& A, 202-214.

Almeida Filho, J. C. P. (2005). O fazer atual da linguística aplicada no Brasil: foco no ensino de línguas. Texto divulgado no II ELARCO, UnB. Mimeo.

Almeida Filho, J. C. P. (1998). Dimensões comunicativas no ensino de línguas. Campinas: Pontes.

Conselho Nacional De Educação. Conselho Pleno. Resolução CNE/CP 2, de 19 de fevereiro de 2002a.

Conselho Nacional De Educação. Conselho Pleno. Resolução CNE/CP 1, de 18 de fevereiro de 2002c. 
DAY, R. R. (1990). Teacher observation in second language teacher education. In D. Nunan \& J. C. Richards (eds) Second language teacher education. Cambridge: CUP, 43-61.

Delors, J, et al. (1996). Educação: um tesouro a descobrir. São Paulo: Cortez; Brasília, DF: MEC, UNESCO.

Freeman, D. 'Mistaken Constructs': Re-examining the nature and assuptions of language teacher education. (mimeo)

FORGRAD. (2000). O currículo como expressão do projeto pedagógico: um processo flexível (2000). In FORGRAD. Resgatando espaços e construindo idéias. Niterói: Eduff, 103-116.

Fórum De Pró-Reitores De Graduação Das Universidades Brasileiras. (2002). Diretrizes para a formação de professores: concepções e implementação. João Pessoa.

Giménez, T. (2004). Tornando-se professores de inglês: experiências de formação inicial em um curso de Letras. In Abrahão, M. H. V. (Org.). Prática de ensino de língua estrangeira: experiências e reflexões. Campinas, SP: Pontes Editores, ArteLíngua.

Krashen, S. (1981). Second Language Acquisition and Learning. Oxford: Pergamon Press.

Laraia, R. B. (1993). Cultura: um conceito antropológico. Rio de Janeiro: Jorge Zahar Editor.

Lüdke, M. (2002). A pesquisa na visão do formador de professores. Anais do XI ENDIPE: Encontro Nacional de Didática e Prática de Ensino. Igualdade e Diversidade na Educação. Goiânia. Maio. CD Rom.

Ministério da Educação. (2006). Secretaria de Educação Básica. Orientações Curriculares para o ensino médio. Linguagem, códigos e suas tecnologias. Cap. 4 Conhecimentos de Espanhol. Brasília. Vol. 1, 125-164.

MEC. Secretaria de Educação Superior. Departamento de Política do Ensino Superior. Esclarecimentos sobre mudanças na dinâmica de trabalho da SESu em decorrência do decreto 3.276/99 e da resolução CP n 01/99 do Conselho Nacional de Educação. s/d.

Mesquita, D. N. C. (2005). Estágio e Ensino e Aprendizagem de inglês na Licenciatura em Letras. Goiânia: UFG, 2005. Tese (Doutorado em Letras e Linguística), Faculdade de Letras, Universidade Federal de Goiás.

Nóvoa, A. (1992). A formação de professores e profissão docente. In A. Nóvoa (Coord) Os professores e sua formação. Lisboa: Publicações Dom Quixote,15- 33. 
Nóvoa, A. (2005). Dilemas actuais dos professores: a comunidade, a autonomia, o conhecimento. Anais do IV Seminário das Licenciaturas. Perspectivas para a Formação de Professores. CDRoon. Goiânia:UCG, 1-10.

Paiva, Vera L. M. (2003). Estágio do curso de Letras. Mensagem para a CVL (Comunidade Virtual da Linguagem), encaminhada em 9 mar 2003.

Paiva, V.L.M.O. (2005). O Novo Perfil dos Cursos de Licenciatura em Letras. In: TOMICH, et (Orgs.). A interculturalidade no ensino de inglês. Florianópolis: UFSC, 345-363 (Advanced Research English Series).

Pimenta, S. G. (Org.). (1994). O estágio na formação de professores: unidade, teoria e prática. São Paulo: Cortez.

Pimenta, S. G. \& Lima, M. S. L. (2004). Estágio e docência. São Paulo: Cortez.

Richards, J. C. (1990). The dilemma of teacher education in second language teaching. In D. Nunan \& J. C. Richards (eds) Second language teacher education. Cambridge: CUP, 3- 15.

UFG, PPP, 2003 www.letras.ufg.br Acessado no dia 07 de março de 2007.

\section{AS AUTORAS:}

Lucielena Mendonça de Lima é professora da área de Espanhol da Faculdade de Letras da Universidade Federal de Goiás desde 1997. Doutora em Filologia Hispânica pela Universidad de Oviedo (Espanha), leciona as disciplinas: Tradução Espanhol/Português, Culturas de língua espanhola, Estágio Supervisionado (Espanhol). Atua, também, como professora e orientadora no programa de Pós-Graduação em Letras e Linguística da UFG.

E-mail: $\underline{\text { lima@letras.ufg.br }}$

Cleidimar Aparecida Mendonça e Silva é professora da área de Espanhol da Faculdade de Letras da Universidade Federal de Goiás desde 2005. Doutoranda em Estudos Linguísticos no programa de Pós-Graduação em Letras e Linguística da UFG, leciona as disciplinas: Estágio Supervisionado (Espanhol) e Língua Espanhola. Atua, também, como professora e orientadora na Especialização em Linguística Aplicada da UFG.

E-mail: cleidimar@letras.ufg.br 